\title{
Cross-National Differences in Gain- Domain Risk Preferences among Older Populations: Judgment and Decision-Making Behaviors in Rapidly Aging Countries
}

Samuel Joo and Suyoung Baek

\section{Abstract}

This research explores the systematic, cross-national differences in choice-inferred risk preferences between American and South Korean ("Korean") elders. A total of four different sample groups-American elders, Korean elders, ${ }^{1}$ American young adults, and Korean young adults -were surveyed. All four groups were asked to partake in a two-part questionnaire: one pertaining to their background information and the other consisting of a set of gain-domain choice questions based on hypothetical lottery situations. The result of the study highlights three statistically

1 The UN agreed cutoff is 60+ years to refer to the older or elderly persons; however, because the study was conducted using convenience sampling, elders in the experiment refer to subjects who are 50 years old and older. 
significant ( $\alpha=0.05)$ findings among the groups surveyed: (1) The Korean elderly group tends to be more risk-averse than the American elderly group, (2) the American elderly group tends to be more risk-seeking than the American young adult group, (3) and the Korean elderly group tends to be more risk-averse than the Korean young adult group.

Keywords: Aging, prospect theory, decisions under risk, South Korean elders, American elders; Eldercare Crisis

\section{Preface}

From 2017 to 2050, the United States will encounter a substantial growth in its elderly population. In 2050, the population aged 65 and over is projected to reach 83.7 million, almost double its population of 49.2 million, recorded in 2016 (U.S. Census Bureau, 2017). Members of the "Baby Boomer"2 generation are largely responsible for such increase in the older population, as they began turning 65 in 2011. At the current rate, $20.3 \%$ of the U.S. population will be aged 65 and over in 2030, and by 2050 , around 84 million people or $21 \%$ of the total population, will be over the age of $85 .^{3}$

\section{Population Aged 65 and Over for the United States: 2012 to $2050^{4}$}






\section{Percent of Population Aged 65 and Over for the United States: 2012 to $2050^{5}$}

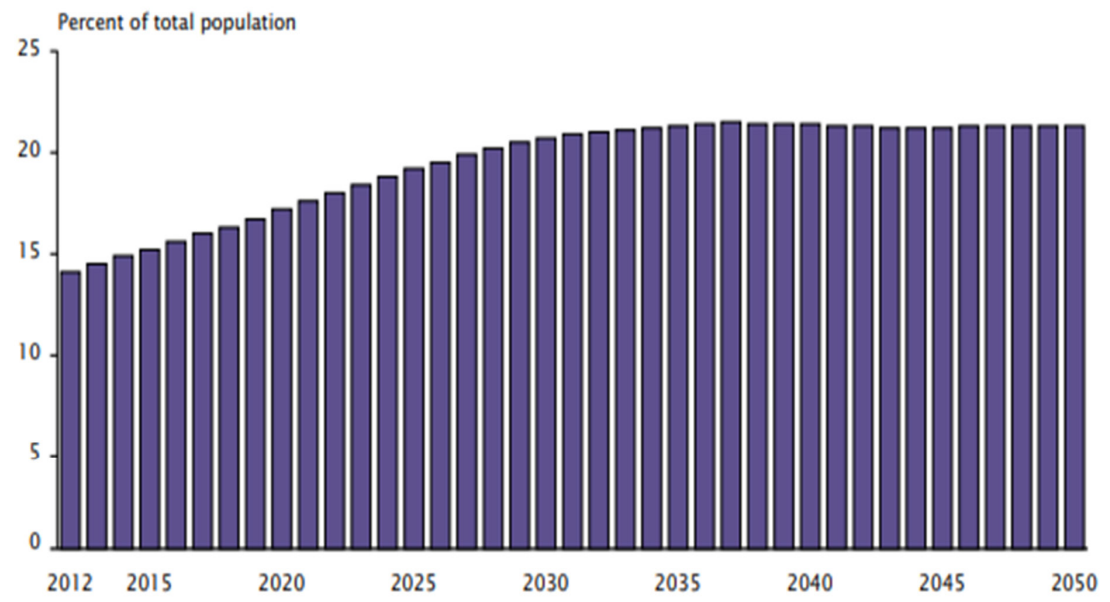

One of the challenges that U.S. public administrators must overcome, relating to this increase in the elderly population, is sustainable budget management. In 2017, approximately $\$ 1.9$ trillion, or $48 \%$ of federal spending, was dedicated to Social Security (\$939 billion), Medicare ( $\$ 591$ billion), and Medicaid ( $\$ 375$ billion), constituting nearly $75 \%$ of all mandatory spending. ${ }^{6}$ These programs and benefits are surely inalienable rights of the elderly citizens and their sustainability is in question. A recent Congressional Research Service report concluded, "under intermediate assumptions, the Hospital Insurance Trust Fund will become insolvent in 2026" (Davis, 2018). ${ }^{7}$

On the other side of the globe, South Korea, as well as China and Japan, has begun its transition into a "Super Aged Society"8 (O'Connor, 2014).

5 U.S. Census Bureau, 2012 Population Estimates and 2012 National Projections.

6 Congressional Budget Office: https://www.cbo.gov/publication/53624

7 Medicare is the nation's health insurance program for persons aged 65 and older and certain disabled persons. Medicare consists of four distinct parts: Part A (Hospital Insurance, or HI); Part B (Supplementary Medical Insurance, or SMI); Part C (Medicare Advantage, or MA); and Part D (the outpatient prescription drug benefit). The Part A program is financed primarily through payroll taxes levied on current workers and their employers; these taxes are credited to the $\mathrm{HI}$ Trust Fund.

8 Also referred to as "Hyper Aged Society" - countries in which more than one in five $(20 \%)$ of the population is 65 or older. 
South Korea's aging phenomenon can be characterized by two features: (1) increasing average life expectancy and (2) a sharp decline in fertility rates. The growing proportion of the elderly population, if it continues at its current rate, could have detrimental impacts on the South Korean economy and public administration - namely a decrease in labor productivity (i.e. reduced GDP per capita) and increased insolvency risk of pension funds. South Korea's average life expectancy at birth has already reached 82.0 years in $2016,{ }^{9} 10$ years higher than the global average life expectancy at birth of 72.0 years. ${ }^{10}$

\section{South Korea Life Expectancy at Birth: 1960 - 2014}

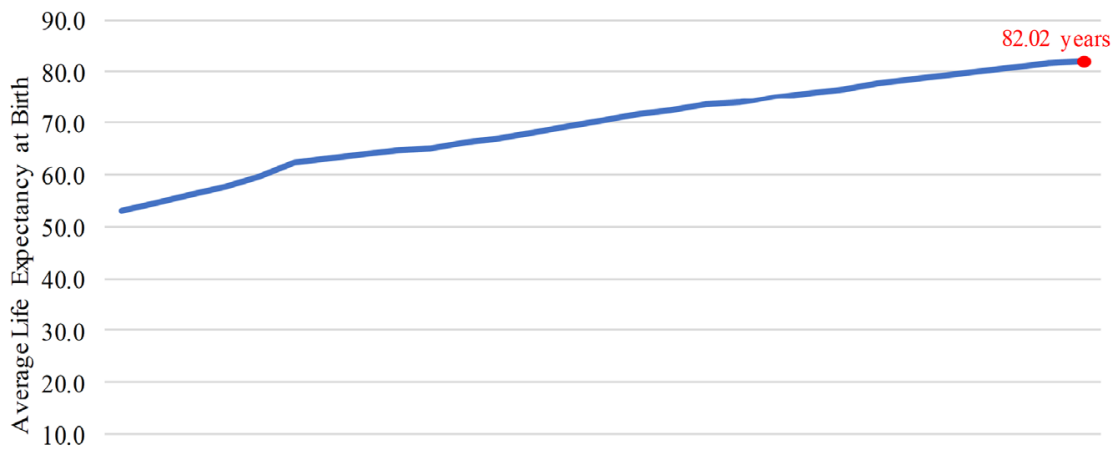

0.0

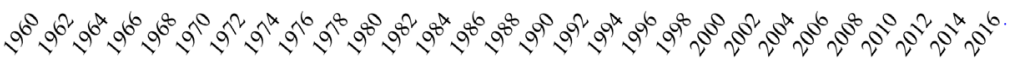

World Bank, https://data.worldbank.org/indicator/SP.DYN.LEoo.IN?locations $=\mathrm{KR}$

Coupled with the increase in average life expectancy, South Korea is also suffering from an unprecedented low fertility rate. ${ }^{11}$ Assuming zero net migration and unchanged mortality, a total fertility rate of 2.1 children per woman generally ensures a stable population level. ${ }^{12}$ However, the national

9 Life Expectancy at Birth: https://data.worldbank.org/indicator

10 World Health Organization - Global Health Observatory (GHO) data: http:// www.who.int/gho/mortality_burden_disease/life_tables/situation_trends/en/ 11 World Health Organization - Global Health Observatory (GHO) data: http:// www.who.int/gho/mortality_burden_disease/life_tables/situation_trends/en/ 12 World Health Organization: http://www.searo.who.int/entity/health_situation_ trends/data/chi/TFR/en/ 
fertility rate of South Korea, as of 2016, is far below this replacement rate, with an average rate of 1.20. Consequently, the old-age dependency ratio is projected to decline sharply in the next couple decades. ${ }^{13}$ In 2017, the ratio of working-age adults to the elderly population in South Korea was 5.2..$^{14}$ This ratio is projected to fall to 4.6 by $2020,2.7$ by 2030 , and to 1.5 by 2050 (O'Conner, 2014).



OECD: https://data.oecd.org/pop/fertility-rates.htm\#indicator-chart

Driven by the low fertility rates and, consequently, low labor productivity, Korea's National Pension Fund is anticipated to peak in $2043(2,607$ trillion won ${ }^{15}$ ) and become completely depleted by $2060 .{ }^{16}$

With populations around the world aging more rapidly than ever before, policymakers confront a number of challenges as they seek to adjust existing policies to better meet the growing needs of the world's changing demographics. Moreover, due to the widespread social and economic implications of an aging population, policymakers struggle to find solutions that can effectively mitigate the myriad problems associated with aging populations. This is especially true when evaluating the impacts of population aging on not only national programs such as

13 The ratio of older dependents (people older than 64 ) to the working-age population (those ages 15-64).

14 Age Dependency Ratio, Old: https://data.worldbank.org/indicator

15 c.US\$2.31 trillion as of November 2, 2018

16 OECD: http://www.oecd.org/finance/private-pensions/47029412.pdf 
pension plans and health insurance programs, but also families, businesses, and health care providers. ${ }^{17}$ According to the 2017 United Nations report concludes that as the average age of populations continues to rise, governments should address the needs of older population-including those related to housing, employment, health care, social protection, and other forms of intergenerational solidarity-by replacing old policies with more effective policies (United Nations, 2017, pg. 1).

Inspired by Daniel Kahneman and Amos Tversky's work on prospect theory, this research aims to explore the implications of rapidly aging societies by examining the choice behaviors under risky (i.e. uncertain) circumstances of the older populations of two distinctly different countries - America and South Korea.

\section{Introduction}

\subsection{Expected Value Maximization and Risk Perception}

An approach to examining the effects of age in risky decision-making is to ask participants to choose between monetary lotteries for which relevant information about risk and reward is explicitly described (e.g., a choice between (a) an option offering a $20 \%$ chance of winning $\$ 1,000$ and nothing otherwise and (b) an option offering a 90\% chance of winning $\$ 150$ and nothing otherwise). Such descriptive analyses of people's risky choices have focused on two key features: (1) quality of decision and (2) risk aversion. Quality of decision is defined as the frequency of which the decision maker selects the option with a higher expected value, defined as:

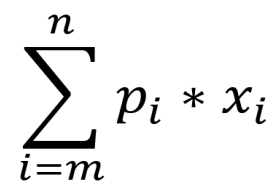

$\mathrm{P} i$ and $\mathrm{xi}$ are the probability and the reward, respectively, associated with each possible outcome of an option. Risk aversion, on the other hand, refers to the decision maker's preference towards options that provide certainty and distaste for those with higher variability in possible outcomes.

17 Appendix A, Disappearing South Korea 


\subsection{Prospect Theory Framework}

In this study, we investigated cross-national differences in risky decision-making between South Korean and American elders. We analyzed the statistical difference between the two elderly groups' risky choices by using the computational modeling framework of cumulative prospect theory (CPT) (Tversky \& Kahneman, 1992). By employing the computational modeling framework, we were able to quantify and visualize the decision-making mechanisms underlying people's choices.

CPT suggests that the objective monetary outcomes of a lottery are transformed into subjective values through a value function, which is defined as:

$$
\sum_{i=m}^{n} p_{i} * U\left(x_{i}\right)
$$

$\mathrm{U}\left(\mathrm{x}_{\mathrm{i}}\right)$ represents a value function, which is often characterized by diminishing marginal utility and by loss aversion, as illustrated in the diagram below. $^{18}$

\section{Prospect Theory Value Function}

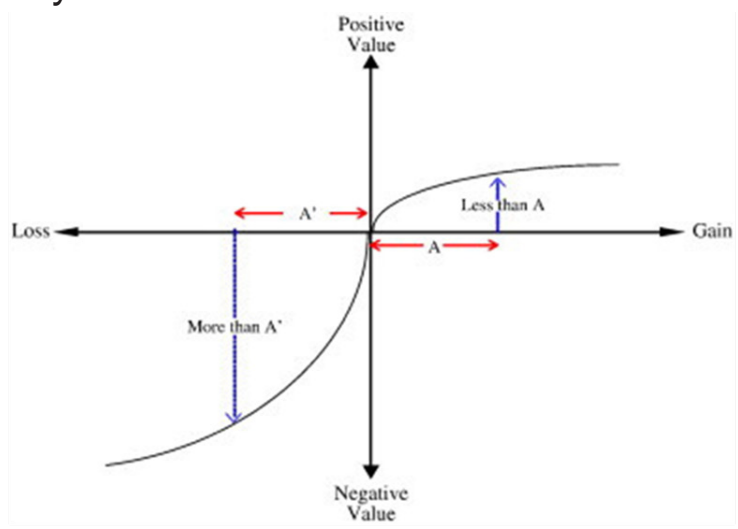

University of Leicester: https://www.le.ac.uk/ec/research/RePEc/lec/leecon/dp10-10.pdf

18 This idea of loss aversion is defined as "the tendency to feel the pain of a loss more intensively than the pleasure of an equal-sized gain" (Rabin and Thaler, 2001). 
CPT also assumes a probability weighting function, defined as:

$$
\sum_{i=m}^{n} \pi_{i} * U\left(x_{i}\right)
$$

$\pi_{i}$ represents a function that transforms objective probabilities into subjective weights, leading to an inverse S-shaped curvature as illustrated in the graph below.

\subsection{The Probability Weighting Function}

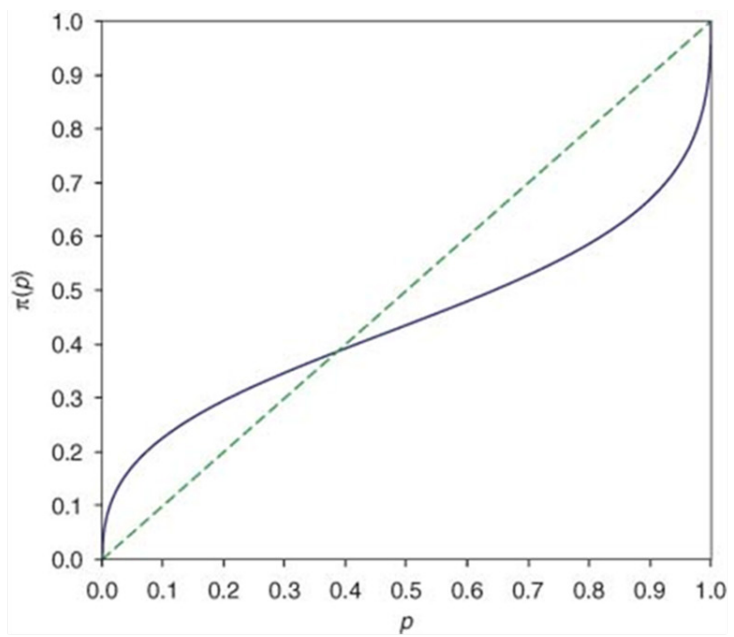

University of Leicester: https://www.le.ac.uk/ec/research/RePEc/lec/leecon/dp10-10.pdf

The dotted-line represents objected probabilities and the solid-line represents the corresponding subjective probabilities. In this diagram, the subjective weight overvalues smaller probabilities and discounts bigger probabilities - the curvature is above the dotted line when the probabilities are low and below as the probabilities increase. These transformed values and probabilities are multiplied to produce an option's overall valuation.

Another component of CPT in quantifying decision-making processes is randomness in decisions, also referred to as "noise." In other words, by quantifying noise, we can understand to what extent risk preference is based on systematic risk-averse or risk-seeking behaviors and to what 
extent it is based on randomness (Bhatia \& Loomes 2017). Using these parameters and mechanisms, this study investigated whether we can quantify the differences in decision-making processes of American and South Korean elders.

\section{Methods and Study}

\subsection{Sampling and Participation}

We employed convenience sampling for this study by collecting samples from comparable settings. In total, we recruited 20 American elders ( 14 females, 6 males) ages 53 to 81 years (Mean $=71.9, \mathrm{SD}=7.2$ ) and 22 Korean elders ( 10 females, 12 males) ages 52 to 69 years $($ Mean $=59.9, \mathrm{SD}$ = 5.1). The American elderly samples were collected from an adult daycare center, called the Northeast Older Adult Center (NEOAC), in Philadelphia, Pennsylvania. The Korean elderly samples were collected from an older adult counseling center, called the 50+ Center, in Seoul, South Korea.

A sample of young adults were also collected from respective countries - we recruited 21 American young adults (11 females, 10 males) ages 18 to 22 (Mean $=20.0, \mathrm{SD}=1.2)$ and 32 Korean young adults (15 females, 17 males) ages 19 and 27 (Mean $=21.4, \mathrm{SD}=1.6)$. The American young adult samples were collected at the University of Pennsylvania in Philadelphia. The Korean young adult samples were collected at Yonsei University, in Seoul, South Korea.

\subsection{Survey}

Given we employed a convenience sampling method, ${ }^{19}$ we included in our experiment a list of survey questions to better understand the myriad education levels, political views, financial satisfaction, religious views, etc. of our samples. Data collected through the survey allowed us to interpret our experiment results in a way that took into account potential sources of variations in risk preferences besides age and national background. These questions were extracted from the World Values Survey with slight modifications to better suit our experiment. ${ }^{20}$

19 A type of non-probability sampling method that relies on data collection from population members who are conveniently available to participate in study. 20 Appendix B: World Values Survey 


\subsection{Translation and Conversion}

For translations of instructions and stimuli, we employed back-translation and decentering method (Brislin, 1970). This method involves translating the source language (i.e. English) to the target language (i.e. Korean) and back, and discrepancies that subsequently occur are addressed through "decentering." Decentering refers to the method of modifying both the source and target language, in multiple interactions, to move away from the idiosyncrasies of the source language (Erkut, 2010). For our stimuli and instructions, which were originally written in English, two different bilingual individuals conducted the translations using the back translations with decentering method.

The market exchange rate from February 4, 2018 (1 USD = 1,083 KRW) was used for the conversions of monetary values of the lotteries between the American dollar and the Korean won, and rounded to the nearest thousand won.

\subsection{Procedure}

Participants were examined in a group setting under the guidance of the experimenters. They were asked to complete a short survey, consisting of 10 questions. Subsequently, they read instructions detailing the risky choice task, procedure, and payoffs. They were encouraged to be thorough and careful in completing the task. Then, participants completed 20 sequentially-presented and randomly-ordered choice problems. Each problem consisted of a pair of two-outcome monetary lotteries, and participants indicated which lottery they preferred. All of the lotteries operated in the positive domain, meaning that they involved no losses, only gains. 
Table 1: Description of Lottery Options in Terms of Their Outcomes (1 and 2), Associated Probability Levels (P1 and P2) and the Options' Expected Values (EV)

\section{Lottery 1}

\begin{tabular}{|c|c|c|c|}
\hline \# & $\begin{array}{c}\text { Outcome } \\
1\end{array}$ & P1 & EV \\
\hline 1 & 120 & $40 \%$ & 48.0 \\
\hline 2 & 60 & $44 \%$ & 26.4 \\
\hline 3 & 10 & $100 \%$ & 10.0 \\
\hline 4 & 30 & $100 \%$ & 30.0 \\
\hline 5 & 15 & $100 \%$ & 15.0 \\
\hline 6 & 10 & $100 \%$ & 10.0 \\
\hline 7 & 50 & $90 \%$ & $45 \%$ \\
\hline 8 & 11 & $100 \%$ & 11.0 \\
\hline 9 & 180 & $9 \%$ & 16.2 \\
\hline 10 & 200 & $100 \%$ & 200.0 \\
\hline 11 & 120 & $87 \%$ & 104.4 \\
\hline 12 & 80 & $2 \%$ & 1.6 \\
\hline 13 & 20 & $100 \%$ & 20.0 \\
\hline 14 & 10 & $100 \%$ & 10.0 \\
\hline 15 & 100 & $31 \%$ & 31.0 \\
\hline 16 & 10 & $100 \%$ & 10.0 \\
\hline 17 & 150 & $7 \%$ & 10.5 \\
\hline 18 & 180 & $50 \%$ & 90.0 \\
\hline 19 & 20 & $79 \%$ & 15.8 \\
\hline 20 & 140 & $100 \%$ & \\
\hline
\end{tabular}

\section{Lottery 2}

$\begin{array}{cccc}\begin{array}{c}\text { Outcome } \\ 2\end{array} & \text { P2 } & \text { EV } & \begin{array}{c}\text { EV Max } \\ \text { Choice }\end{array} \\ 50 & 100 \% & 50.0 & 2 \\ 90 & 17 \% & 15.3 & 1 \\ 200 & 2 \% & 4.0 & 1 \\ 100 & 30 \% & 30.0 & \text { no diff } \\ 16 & 98 \% & 15.7 & 2 \\ 170 & 4 \% & 6.8 & 1 \\ 40 & 100 \% & 40.0 & 1 \\ 15 & 70 \% & 10.5 & 1 \\ 120 & 64 \% & 76.8 & 2 \\ 30 & 60 \% & 18.0 & 1 \\ 190 & 86 \% & 163.4 & 2 \\ 40 & 29 \% & 11.6 & 2 \\ 150 & 10 \% & 15.0 & 1 \\ 20 & 97 \% & 19.4 & 2 \\ 6 & 74 \% & 4.4 & 1 \\ 12 & 5 \% & 0.6 & 1 \\ 10 & 100 \% & 10.0 & 1 \\ 90 & 100 \% & 90.0 & \text { no diff } \\ 150 & 44 \% & 66.0 & 2 \\ 90 & 65 \% & 58.5 & 1\end{array}$

The above table summarizes the outcomes of each pair of lotteries and their corresponding expected values based on the probabilities of winning the lottery. As in the cases for lottery pairs \#4 and \#18, people should be indifferent between Lottery 1 and Lottery 2 as they both offer the same expected values when viewed strictly from an expected-value perspective. 
To ascertain the attentiveness of the participates, the lotteries included two "attention tests," which offered definitively superior option. ${ }^{21}$ All surveys that failed either one of the "attention tests" were excluded from the analysis.

The information obtained was used to make both inter-ethnic and inter-generational comparisons regarding the risk preferences of each surveyed group. In other words, the American elderly sample group was compared against both the Korean elderly sample group and the American young adult sample group. Likewise, the Korean elderly sample group was compared against both the American elderly sample group and the Korean young adult sample group. All of the comparisons were made using a series of unpaired sample t-tests.

\section{Results and Discussion}

\subsection{Survey and Participant Observations}

The survey results revealed the following characteristics among our elderly samples and our young adult groups:

Table 2: Summary of Participant Survey Results

\begin{tabular}{|c|c|c|}
\hline $\begin{array}{l}\text { U.S. } \\
\text { Elderly }\end{array}$ & $\begin{array}{l}\text { Korean } \\
\text { Elderly }\end{array}$ & $\begin{array}{c}\text { U.S. } \\
\text { Young } \\
\text { Adults }\end{array}$ \\
\hline
\end{tabular}

$\begin{array}{lllll}\text { N: } & 20 & 22 & 21 & 32\end{array}$

(Average; SD)

Age:

$71.9 ; 7.2 \quad 59.9 ; 5.1 \quad 20.0 ; 1.2 \quad 21.4 ; 1.6$

Gender:

Female: Female: 10; Female: 11; Female: 15; 14; Male: 6 Male: 12 Male: $10 \quad$ Male 17

21 For example, one of the "attention tests" offered the following pairs of lotteries: (1) $100 \%$ chance of winning $\$ 200$ or (2) $60 \%$ chance of winning $\$ 60$; corresponding "attention tests" were offered in the Korean version of the lotteries.

14 SPICE | Philosophy, Politics and Economics Undergraduate Journal 
Table 2: Summary of Participant Survey Results

$\begin{array}{cccc}\text { U.S. } & \text { Korean } & \begin{array}{c}\text { U.S. } \\ \text { Young }\end{array} & \begin{array}{c}\text { Korean } \\ \text { Young } \\ \text { Elderly }\end{array} \\ & \text { Elderly } & \text { Adults } & \text { Adults }\end{array}$

\section{Ethnicity:}

White

15

N/A

11

$\mathrm{N} / \mathrm{A}$

Hispanic or Latino

2

$\mathrm{N} / \mathrm{A}$

Black or African American

2

$\mathrm{N} / \mathrm{A}$

N/A

Native American or American Indian

0

$\mathrm{N} / \mathrm{A}$

N/A

Asian/Pacific Islander

0

N/A

N/A

Other

$N / A$

N/A

1

3

N/A

Highest Education Level:

No formal education

0

0

0

Less than high school

degree

1

High school degree or

equivalent (e.g. GED)

6

Some college but no

degree

4

Associate Degree

3

Bachelor's Degree

6

Some graduate school

but no degree

o

Graduate degree

0

O

1

0

0

31

0

\section{Political Party:}

$\begin{array}{lcccc}\text { Republican } & 4 & \text { N/A } & 3 & \text { N/A } \\ \text { Democrat } & 13 & \text { N/A } & 14 & \text { N/A } \\ \text { Independent } & 3 & \text { N/A } & 3 & \text { N/A } \\ \text { Other Party } & 0 & \text { N/A } & 0 & \text { N/A } \\ \text { No Party } & 0 & \text { N/A } & 1 & \text { N/A } \\ \text { Not Sure } & 0 & \text { N/A } & 0 & \text { N/A }\end{array}$


Table 2: Summary of Participant Survey Results

$\begin{array}{cccc}\begin{array}{c}\text { U.S. } \\ \text { Elderly }\end{array} & \begin{array}{c}\text { Korean } \\ \text { Elderly }\end{array} & \begin{array}{c}\text { U.S. } \\ \text { Young } \\ \text { Adults }\end{array} & \begin{array}{l}\text { Korean } \\ \text { Young } \\ \text { Adults }\end{array} \\ 2.4 ; 0.6 & 6.0 ; 2.6 & 1.6 ; 0.7 & 5.5 ; 2.0\end{array}$

Political Views:

$5.5 ; 2.0$

\section{Number of Children:}

\begin{tabular}{lllll}
0 & 6 & 0 & 21 & 32 \\
1 & 1 & 5 & 0 & 0 \\
2 & 7 & 15 & 0 & 0 \\
3 & 2 & 1 & 0 & 0 \\
4 & 3 & 2 & 0 & 0 \\
5 & 0 & 0 & 0 & 0 \\
6 & 0 & 0 & 0 & 0 \\
7 & 0 & 0 & 0 & 0 \\
$8+$ & 1 & 0 & 0 & 0 \\
\hline
\end{tabular}

Financial Satisfaction:*

$7.4 ; 2.5$

$6.6 ; 2.2$

$6.9 ; 2.8$

$6.8 ; 1.4$

\section{Economic Class:}

$\begin{array}{lcccc}\text { Upper Class } & 1 & 2 & 2 & 0 \\ \text { Upper Middle Class } & 7 & 8 & 9 & 24 \\ \text { Lower Middle Class } & 10 & 12 & 6 & 5 \\ \text { Working Class } & 2 & 0 & 2 & 3 \\ \text { Lower Class } & 0 & 0 & 2 & 0 \\ \text { Religious Views: } & & & 8 & 21 \\ \begin{array}{l}\text { Do not belong to a de- } \\ \text { nomination }\end{array} & 0 & 6 & 6 & 3 \\ \begin{array}{l}\text { Roman Catholic } \\ \text { Protestant }\end{array} & 15 & 10 & 2 & 6 \\ \begin{array}{l}\text { Orthodox (Russian/Greek/ } \\ \text { etc.) }\end{array} & 0 & 0 & 0 & 0 \\ \text { Jew } & & 0 & 5 & 0 \\ \text { Muslim } & 0 & 0 & 0 & 0\end{array}$


Table 2: Summary of Participant Survey Results

$\begin{array}{ccc}\text { U.S. } & \text { Korean } & \text { U.S. } \\ \text { Elderly } & \text { Elderly } & \begin{array}{c}\text { Young } \\ \text { Adults }\end{array}\end{array}$

Korean

Young

Adults

Hindu

Buddhist

O

0

0

0

0

2

0

2

Other

2

0

0

0

\section{Religious Degree:}

A religious person

Not a religious person

* Scale between 1 (Completely Dissatisfied) and 10 (Completely Satisfied).

As displayed in the summary above, some questions in the first part of the questionnaire-including the one about one's ethnicity and the other about one's political party affiliation-were dropped from the questionnaire distributed to the Korean elderly and the Korean young adult sample groups because both the ethnic makeup and politics of the United States are not comparable to those of South Korea. Further, a few areas that show the highest variance among the samples are the following: age, education, number of children, religion, and the degree of religiousness.

Despite our best efforts to collect the two elderly samples from similar settings, by choosing comparable locations in Philadelphia and Seoul, there was a notable age gap between the American elderly samples and the Korean elderly samples. The difference between the average age of the American and Korean elderly sample groups was 12.0 years. The elderly samples also had notable differences in their levels of education achieved. Only six participants of the American elderly sample group had received bachelor's degrees, whereas all the Korean elderly participants had received bachelor's or graduate degrees. Moreover, although the average number of children between the two elderly groups are the same (2.05 children per sample), American elderly samples have higher variance in the number of children, ranging between zero and eight, compared to the Korean elderly samples' range of one and four. Lastly, the American 
elderly sample group was predominantly Catholic, whereas the Korean sample group was largely Protestant.

The degrees of religiousness between (1) the elderly and young adult samples and the (2) American and Korean groups exhibit meaningful differences. Generally, the elderly sample groups are more religious than the young adult sample groups, and the American sample groups are more religious than the Korean sample groups.

The implications of these variances among the sample groups to the results of the study have not been examined and require further discussion in future research.

3.2 Choice Behavior: Quality of Decisions under Uncertainty

Table 3: Average Participant Choice

Lottery \# U.S. Elderly Korean Elderly Adults

(Average; SD)

$\begin{array}{llllcc}1 & 1.70 ; 0.47 & 1.86 ; 0.35 & 1.95 ; 0.22 & 1.75 ; 0.44 & 2 \\ 2 & 1.25 ; 0.44 & 1.18 ; 0.39 & 1.29 ; 0.46 & 1.16 ; 0.37 & 1 \\ 3 & 1.25 ; 0.44 & 1.23 ; 0.43 & 1.48 ; 0.51 & 1.38 ; 0.49 & 1 \\ 4 & 1.30 ; 0.47 & 1.23 ; 0.43 & 1.24 ; 0.44 & 1.44 ; 0.50 & \text { no diff } \\ 5 & 1.45 ; 0.51 & 1.23 ; 0.43 & 1.24 ; 0.44 & 1.34 ; 0.48 & 2 \\ 6 & 1.25 ; 0.44 & 1.23 ; 0.43 & 1.52 ; 0.51 & 1.38 ; 0.49 & 1 \\ 7 & 1.60 ; 0.50 & 1.86 ; 0.35 & 1.71 ; 0.46 & 1.59 ; 0.50 & 1 \\ 8 & 1.60 ; 0.50 & 1.05 ; 0.21 & 1.10 ; 0.30 & 1.19 ; 0.40 & 1 \\ 9 & 1.60 ; 0.50 & 2.00 ; 0.00 & 2.00 ; 0.00 & 1.97 ; 0.18 & 2 \\ 10 & 1.00 ; 0.00 & 1.00 ; 0.00 & 1.00 ; 0.00 & 1.00 ; 0.00 & 1 \\ 11 & 1.80 ; 0.41 & 1.91 ; 0.29 & 1.95 ; 0.22 & 1.97 ; 0.18 & 2 \\ 12 & 1.75 ; 0.44 & 1.82 ; 0.39 & 1.76 ; 0.44 & 1.81 ; 0.40 & 2 \\ 13 & 1.30 ; 0.47 & 1.09 ; 0.29 & 1.29 ; 0.46 & 1.38 ; 0.49 & 1 \\ 14 & 1.45 ; 0.51 & 1.64 ; 0.40 & 1.86 ; 0.36 & 1.88 ; 0.34 & 2\end{array}$

Korean Young

EV Max Choice Adults 
Table 3: Average Participant Choice

$\begin{array}{cccccc}\text { Lottery \# } & \begin{array}{c}\text { U.S. } \\ \text { Elderly }\end{array} & \begin{array}{c}\text { Korean } \\ \text { Elderly }\end{array} & \begin{array}{c}\text { U.S. Young } \\ \text { Adults }\end{array} & \begin{array}{c}\text { Korean } \\ \text { Young } \\ \text { Adults }\end{array} & \begin{array}{c}\text { EV Max } \\ \text { Choice }\end{array} \\ 15 & 1.55 ; 0.51 & 1.82 ; 0.39 & 1.90 ; 0.30 & 1.78 ; 0.42 & 2 \\ 16 & 1.35 ; 0.49 & 1.09 ; 0.29 & 1.33 ; 0.48 & 1.47 ; 0.51 & 1 \\ 17 & 1.80 ; 0.41 & 1.82 ; 0.39 & 1.67 ; 0.48 & 1.59 ; 0.50 & 1 \\ 18 & 1.85 ; 0.37 & 1.91 ; 0.29 & 1.67 ; 0.48 & 1.75 ; 0.44 & \text { no diff } \\ 19 & 1.35 ; 0.49 & 1.50 ; 0.51 & 1.57 ; 0.51 & 1.81 ; 0.40 & 2 \\ 20 & 1.00 ; 0.00 & 1.00 ; 0.00 & 1.00 ; 0.00 & 1.00 ; 0.00 & 1\end{array}$

The above table illustrates the average choices made by different sample groups between choice 1 (i.e. lottery 1 ) and 2 (i.e. lottery 2 ), and their associated standard deviations.

\section{Average Participant Choices vs. Expected Value Maximizer}



*Shaded areas illustrate indifference between Lottery 1 and 2

The above graph juxtaposes the average choices of our four sample groups to the choices of an Expected Maximizer ("EV"), one who makes choices purely based on expected value. The red shaded bars in the graph represent 
EV's indifference to choices. For example, lottery pair \#4 provided the following outcomes:

Lottery 1

$\begin{array}{cccc}\text { \# } & \text { Outcome 1 } & \text { P1 } & \text { EV } \\ \mathbf{4} & 30 & 100 \% & 30.0 \\ \mathbf{8} & 180 & 50 \% & 90.0\end{array}$

\section{Lottery 2}

$\begin{array}{ccc}\text { Outcome } 2 & \text { P2 } & \text { EV } \\ 100 & 30 \% & 30.0 \\ 90 & 100 \% & 90.0\end{array}$

Because the expected value of the two lotteries are equal, an EV would be indifferent to either choices and should have no preference between the two. However, such lottery choices allow experimenters to better understand the choice behavior tendencies of subjects and examine their risk-seeking or risk-averse preferences.

As previously mentioned, the quality of the decisions observed among the sample groups appear to be similar, adhering to pursuing maximum expected value on average. Equally important, when examining these two "indifference choices," was that all four samples tended to elicit riskaverse choice behaviors by choosing the certain option (i.e. lottery with $100 \%$ outcome certainty).

Choices for other lotteries, namely lottery pairs 5, 7 and 17, also suggest that all four samples exhibited strong risk-averse tendencies and preference for certainty.

Lottery 1

$\begin{array}{cccc}\text { \# } & \text { Outcome 1 } & \text { P1 } & \text { EV } \\ \mathbf{5} & 15 & 100 \% & 15.0 \\ \mathbf{7} & 50 & 90 \% & 45.0 \\ \mathbf{1 7} & 150 & 7 \% & 10.5\end{array}$

\section{Lottery 2}

$\begin{array}{ccc}\text { Outcome 2 } & \text { P2 } & \text { EV } \\ 16 & 98 \% & 15.7 \\ 40 & 100 \% & 40.0 \\ 10 & 100 \% & 10.0\end{array}$

As illustrated in the table above, despite the lower expected values of the lotteries, all four sample groups were inclined to choose certain options. Provided below are unpaired sample t-tests to show whether there was any statistical significance between choices of the samples. 
Table 4: Unpaired Sample T-Test of Sample Choices*



* Lottery \# 10 and \# 20 were excluded from the sample T-Test because they were attention tests, in which all respondents made the same choice.

The highlighted cells indicate sample T-Tests in which the results were below our target alpha $(\alpha=0.05)$. 
American Elderly vs. Korean Elderly

Lottery 1

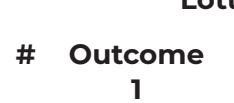

8110

9180

16
Lottery 2

EV Outcome P2 2

150

120

120
P2 EV

\begin{tabular}{ll}
$70 \%$ & 105.0 \\
$64 \%$ & 76.8 \\
\hline 5 & 6.0
\end{tabular}

Avg. Choice

U.S. Korean Elderly Elderly

1.60

1.05

$1.60 \quad 2.00$

$1.35 \quad 1.09$

The three choices $(8,9$ and 16$)$ in which the American and Korean elderly samples differed with statistical significance $(\alpha=0.05)$, suggest that Korean elders were more risk-averse and tended to choose options with the highest probability.

American Elderly vs. American Young Adults

Lottery 1

\# Outcome

1

$\begin{array}{cc}\mathbf{1} & 120 \\ \mathbf{8} & 110 \\ \mathbf{1 4} & 10 \\ \mathbf{1 5} & 100\end{array}$

15100

P1
EV

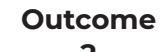

2

Lottery 2

P2

EV

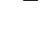

50

150

20

60
Avg. Choice

U.S. U.S. Elderly Young

Adult

1.95

1.10

1.86

1.90

The American elderly sample group was compared against its corresponding control group, the American young adult sample group. An unpaired sample $t$-test of the two groups showed that four choice behaviors ( 1 , $8,14$ and 15$)$ were statistically significant in their difference $(\alpha=0.05)$, and of the four, three choices (1, 8 and 15) showed that American elderly employed more risk-seeking behaviors compared to the control group. A possible explanation for the outcome of lottery 14, in which American Elders elicited more risk-averse choice behaviors, is randomness, or "noise." 
Korean Elderly vs. Korean Young Adults

Lottery 1

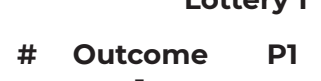

13

16

19
1

P1

EV



$7 \quad 50$

1320

1610



Outcome

\begin{tabular}{rr}
$90 \%$ & 45.0 \\
$100 \%$ & 20.0 \\
$100 \%$ & 10.0 \\
\hline $79 \%$ & 15.8
\end{tabular}

$79 \% \quad 15.8$
2

Lottery 2

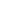

40

150

120

150
P2 EV

EV

$100 \% \quad 40.0$

$10 \% \quad 15.0$

$5 \% \quad 6.0$

$44 \% \quad 66.0$
Avg. Choice

$\begin{array}{ll}\text { Korean } & \begin{array}{l}\text { Korean } \\ \text { Elderly } \\ \text { Young } \\ \text { Adult }\end{array}\end{array}$

1.86

1.59

1.38

1.47

1.81

There were four lottery choices that had statistically significant difference between the Korean elderly and Korean young adult sample groups. Unlike the American elderly sample group, Korean elderly samples employed more risk-averse choice tendencies, with average elder choosing the lottery that provided the highest probability.

\section{American Young Adults vs. Korean Young Adults}

There is insufficient evidence for any meaningful differences between the American and Korean young adult sample groups, given that there was only one statistically significant difference in their lottery choice patterns.

\subsection{Impact of Culture and Age on Perception of Risk}

The literature on people's risk preferences and potential sources of variations within these tendencies suggest that there is a myriad of evidence for a number of theories, but there is no consensus about the most significant factors influencing risk preferences. In particular, a large amount of research present findings on whether age and national background influence people's risk preferences. As for whether age plays a role, there are no definitive findings on how age shapes people's decision-making under risk. Some suggest that age positively correlates with the intensity of risk aversion (Albert and Duffy, 2012; Deakin, Aitken, Robbins, and Sahakian, 2004; Best Charness, 2015). Other studies, however, deny this association, suggesting that age either does not play a significant role in shaping people's risk tendencies (Hong, Kubik, and Stein, 2001; Guiso, Haliassos, Jappelli and Claessens, 2003; Schneider, Fehrenbacher, and 
Weber, 2017; Schildberg-Horisch, 2018) or that risk-taking increases with age (Bommier and Rochet, 2003).

On the other hand, it seems pretty apparent that culture, especially as it relates to the different levels of individualism ${ }^{22}$ and collectivism ${ }^{23}$ it embodies, correlates with certain risk-taking attitudes at least in the investment domain (Hsee and Weber, 1998; Hofstede, 1980; Rieger et al., 2014; Schneider, Fehrenbacher, and Weber, 2017; Park, Kim, and Zhang, 2015). Mainly described in terms of the "cushioning effect," studies investigating the role of culture and national background on risk-taking tendencies suggest that the greater one's ability to draw from his or her social or state support networks, the more he or she is likely to engage in risk-taking behaviors (Hsee and Weber, 1998; Hofstede, 1980; Rieger et al., 2014; Schneider, Fehrenbacher, and Weber, 2017; Park, Kim, and Zhang, 2015). To test Hofstede's cushioning effect, Hsee and Weber (1998) conducted a study examining the preference for risky options in respondents from four different countries known to vary on the social individualism-to-collectivism continuum - the U.S., China, Germany, and Poland (Hofstede, 1980). Based on Hofstede's cushioning effect, Hsee and Weber (1998) predicted that in socially-collectivist cultures like China, individuals would have a stronger personal network, through which they can receive help if encountered with a large and possibly catastrophic loss after selecting a risky option (pg. 1208). In accordance with their hypothesis, their study results indicated that Chinese respondents were least risk-averse and the Americans and Germans the most riskaverse of the four cultures (Hsee and Weber, 1998).

As illustrated above, there are several studies exploring the impacts of age and culture in decision-making processes; however, their conclusions vary widely, and there has not been a study conducted to examine the differences in risk preferences for South Korean and American elders.

22 Individualism emphasizes personal freedom and independence (Hsee and Weber, 1999).

23 Collectivism endorses social relatedness and interdependence with others in one's family, community or other social groups (Hsee and Weber, 1999). 


\subsection{Limitations}

\section{Limited Choices of Elderly Care Facilities}

As explained briefly in Section 3.1 Survey and Participant Observations, there were a few limitations that occurred due to the challenges of gaining access to elderly care facilities. Because most of the elderly care facilities in both the United States and South Korea are sensitive about sharing their clients' information, it was difficult to gain permission to collect data from such facilities. After going through an arduous process of gaining approval from several of the facilities that responded to our initial survey request, we narrowed down our locations based on how similar the facilities are in terms of (1) the kinds of services they provide and (2) the types of people who patronize the facility. Of these two criteria, the former is particularly important because the type of services provided by a facility largely dictates what type of people visit the place. For example, if the facility were oriented towards providing healthcare services, then elders who are more health conscious would self-select to be at the facility. If the facility were focused on providing career opportunities for the elderly, then it perhaps may attract more motivated and relatively healthier elders to the facility.

Given the small pool of options that were available to us, there were a number of ineliminable differences between the two facilities we selected - the Northeast Older Adult Center (NEOAC) and the 50+ Center, in Seoul, South Korea. While the kinds of activities and services available at the facilities overlapped considerably, the average ages of the people who are regular visitors at the two facilities differed significantly. Such discrepancy rendered the process of matching the characteristics of the American elderly sample with those of the Korean elderly sample difficult. This is a significant limitation in that the age gap could be partly responsible for the differences in the two groups' risk preferences. Further experimentation, therefore, is recommended to reduce such margin of error.

\section{Procedural Differences}

Another limitation in our elderly sample collection can be attributed to the differences in the settings in which we conducted the survey and the 
experiment. At the Northeast Older Adult Center, we had to collect the data individually, asking the people one by one to complete the survey and the experiment. At the 50+ Center, all of the participants completed the survey and the experiment at the same time. The inability to carry out the survey and the experiment in a comparable manner could have influenced the decisions of the American and the Korean elderly samples. Future studies should aim to eliminate this procedural difference for more accurate analyses of the results.

\section{Conclusion}

Findings from this study suggest that there are statistically significant choice behavior tendencies in risk preferences between the two elderly samples - Korean elderly tend to be more risk-averse than American elderly. The significance of this study also lies with the fact that this study, to the best of our knowledge, is the first of its kind to examine cross-national choice behavior differences between South Korean and American elders. Note, however, that the implications around convenience sampling and other limitations of the study preclude us from making any definitive, generalized conclusions. Yet, this study does raise insightful considerations relating to aging populations.

One of the key concerns pertaining to rapidly aging populations, as indicated previously, is the increasing national healthcare expenditures and the declining economic growth. ${ }^{24}$ National health expenditures, for example, grew $3.9 \%$ to $\$ 3.5$ trillion in 2017 , and accounted for $17.9 \%$ of Gross Domestic Product (GDP). Further, national health spending is projected to grow at an average rate of 5.5 percent per year in the following decade and reach $\$ 6.0$ trillion by $2027 .{ }^{25}$

One approach to recalibrating the consumption levels of healthcare, at least from an economist's perspective, is by making the consumers bear more of the cost of healthcare (i.e. increased copayment requirement in healthcare insurance programs, which your health insurance may require

24 Includes healthcare related expenditures, such as Medicare, Medicaid, private health insurance spending and out-of-pocket expenses.

25 https://www.cms.gov/research-statistics-data-and-systems/statistics-trendsand-reports/nationalhealthexpenddata/nhe-fact-sheet.html 
you to pay in order to receive a specific medical service or supply). ${ }^{26}$ Entertain a scenario in which copayment requirements of all healthcare insurance programs increase. All else remaining the same and putting aside all moral questions surrounding the accessibility of healthcare, this increase would naturally reduce the number hospital visits as fewer people can afford to pay the increased copayment amount. Findings from this study suggest that such calibrations to decrease overall healthcare consumption may be less effective in South Korea than in America. Since South Korean elders have demonstrated to be more risk averse, they may be more willing to bear the extra cost of such copayment requirements, whereas more risk-seeking American elders may choose to take the gamble and visit the hospital less frequently upon such cost increases.

Secondly, such differences in risk preference may have implications in the spending patterns of the elderly population. More risk averse elders may choose to spend less, invest less, and save more. Or, they may choose to invest more heavily in bonds than stocks. Such reduction in spending amounts and equity investment activities can potentially further aggravate the anticipated slowdown of economic growth at aging countries, as alluded to in the preface.

As several countries around the globe are undergoing rapidly aging populations, understanding distinguishable choice behaviors of the elderly populations is becoming increasingly relevant and critical to our society's ability to prepare for the future. Provided, we believe this study presents meaningful guidance and has opened several questions to be answered in other empirical studies pertaining to the elderly demographics.

26 OpenCourseWare, MIT. Lec 3 | MIT 14.01SC Principles of Microeconomics. YouTube, 24 Jan. 2012, www.youtube.com/watch?v=Ye4vL7u6N2g. 


\section{References}

Albert, M.S., and Duffy, J. (2012, January). Differences in Risk Aversion between Young and Older Adults. Neuroscience and Neuroeconomics, U.S. National Library of Medicine. Retrieved from www.ncbi.nlm.nih.gov/ pmc/articles/PMC3852157/.

Bennett, I., Howard, J., \& Howard, D. (2007). Age-Related Differences in Implicit Learning of Subtle Third-Order Sequential Structure. The Journals of Gerontology Series B Psychological Sciences and Social Sciences, 62(2), P98-103. Retrieved from academic.oup.com/psychsocgerontology/article/62/2/P98/548966.

Best, R, and Charness, N. (2015, Sept.), Age Differences in the Effect of Framing on Risky Choice: A Meta-Analysis. Psychology and Aging, U.S.National Library of Medicine. Retrieved from www.ncbi.nlm.nih.gov/ pubmed/26098168.

Bhatia, S., and Loomes, G. (2017). Noisy Preferences in Risky Choice: A Cautionary Note. Psychological Review, 124. doi:10.1037/rev0000073.supp

Bommier, A., and Jean-Charles R. (2003, October). Why Older People Seem to Be Less Risk Averse? Universite Universit'e des Sciences. Retrieved from https://www.ifs.org.uk/conferences/rtn_bommier.pdf

Brislin, R. W. (1970). Back-Translation for Cross-Cultural Research. Journal of Cross-Cultural Psychology, 1(3), 185-216. doi:10.1177/135910457000100301

Chou, K.-L., Lee, T. M., \& Ho, A. H. Y. (2007). Does Mood State Change Risk Taking Tendency in Older Adults? Psychoogy and Aging, 22(2), 310-318. Retrieved from psycnet.apa.org/record/2007-07952-010.

Davis, P.A. (2018, June 18). Medicare: Insolvency Projections. Congressional Research Service, Medicare: Insolvency Projections. 
Erkut, Sumru. (2010). Developing Multiple Language Versions of Instruments for Intercultural Research. Child Development Perspectives, (4)1, 19-24.

Forgas, J.P., and George J.M. (2001). Affective Influences on Judgments and Behavior in Organizations: An Information Processing Perspective. Organizational Behavior and Human Decision Processes, 86(1), 3-34.

Hartshorne, J.K., and Germine L.T. (2015, March 13). When Does Cognitive Functioning Peak? The Asynchronous Rise and Fall of Different Cognitive Abilities across the Lifespan." Psychological Science, 26(4), 433-443. PMC. Web. 20 Jan. 2018.

Hofstede, G. (1980). Culture's Consequences. Sage Publications, Beverly Hills, CA.

Hsee, C. K. and Weber, E. U. (1998). Cross-Cultural Differences in Risk Perception, but Cross-Cultural Similarities in Attitudes Towards Perceived Risk. Management Science, 44(9), 1205-1217.

Hsee, C. K. and Weber, E. U. (1998). Cross-National Differences in Risk Preference and Lay Predictions. Journal of Behavioral Decision Making, $12(2), 165-179$.

Kunzmann, U et al. (2000, September). Is Age-Related Stability of Subjective Well-Being a Paradox? Cross-Sectional and Longitudinal Evidence from the Berlin Aging Study. Psychology and Aging, U.S. National Library of Medicine. Retrieved from www.ncbi.nlm.nih.gov/pubmed/11014714.

Li, Y, et al. (2013, September). Complementary Cognitive Capabilities, Economic Decision Making, and Aging. Psychology and Aging, U.S. National Library of Medicine. Retrieved from www.ncbi.nlm.nih.gov/ pubmed/24040999.

Park, J., Kim, D., \& Zhang, C. (2015). Understanding Cross-National Differences in Risk Through a Localized Cultural Perspective. Cross-Cultural Research. doi:10.1177/1069397115609560 
Rieger, M.O., Wang, M. and Hens, T. (2014). Risk Preferences Around the World, Management Science, 61(3), 1-12.

Sarah, O. (2014, August 06). World will have 13 'super-aged' nations by 2020. Retrieved from https://www.ft.com/content/f356f8ao-1d8c-11e48foc-00144feabdco

Schneider, C. R., Fehrenbacher, D. D., \& Weber, E. U. (2017). Catch me if I fall: Cross-national differences in willingness to take financial risks as a function of social and state 'cushioning'. International Business Review, 26(6), 1023-1033. doi:10.1016/j.ibusrev.2017.03.008

Tversky, A. and Kahneman D. (1992). Advances in Prospect Theory: Cumulative Representation of Uncertainty. citeseerx.ist.psu.edu/viewdoc/ download?doi=10.1.1.320.8769\&rep=rep1\&type=pdf.

US Census Bureau. (2018, April 10). The Nation's Older Population Is Still Growing, Census Bureau Reports. Retrieved from http://www.census.gov/ newsroom/press-releases/2017/cb17-100.html

"Demography - Fertility Rates - OECD Data." The OECD, data.oecd.org/ pop/fertility-rates.htm.

"NHE-Fact-Sheet." (2017, December 6). CMS.gov Centers for Medicare \& Medicaid Services. www.cms.gov/research-statistics-data-and-systems/ statistics-trends-and-reports/nationalhealthexpenddata/nhe-factsheet.html. 


\section{Appendix A: Disappearing South Korea}

South Korea's population is experiencing a demographic phenomenon in which mortality and fertility rates decline from higher to lower levels. Decreasing fertility, along with lengthening life expectancy, has reshaped the age structure of the South Korean population by shifting relative societal weight from younger to older groups.

South Korea's population is experiencing a demographic phenomenon in which mortality and fertility rates decline from higher to lower levels. Decreasing fertility, along with lengthening life expectancy, has reshaped the age structure of the South Korean population by shifting relative societal weight from younger to older groups.

\section{South Korea Changes in Elderly Population}

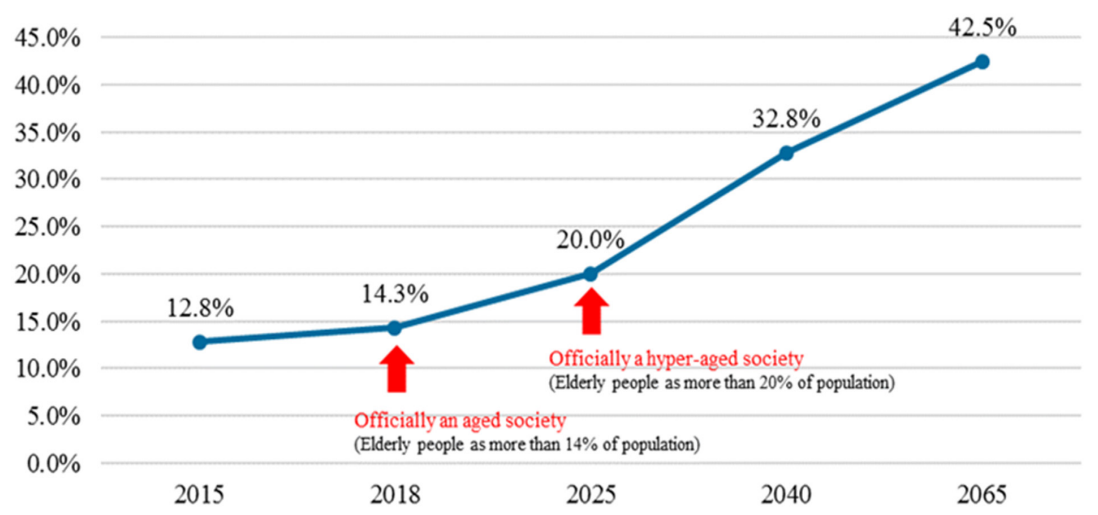

Department of Statistics, South Korea

The South Korean population increased from 31.43 million in 1970 to 47.99 million in 2010. The elderly population ( $65+$ years) more than tripled, from $3.31 \%$ in 1970 to $11.30 \%$ in 2010 . The population of children (0-15 years), on the other hand, decreased by more than half, from $42.12 \%$ in 1970 to $16.23 \%$ in 2010. As a result of these changes, South Korea's Department of Statistics estimates that approximately $20 \%$ of South Korea's population will be comprised of elders by 2020. By 2040 and 2065 the elderly pop- 
ulation is projected to grow to $32.8 \%$ and $42.5 \%$ of the total population, respectively. On the other hand, the population of students (6-21 years) is projected to decrease from 8.92 million from 2015 to 7.08 million in 2020 and to 6.55 million in 2035 .



Department of Statistics, South Korea

Although South Korea is one of the first countries to experience this demographic transition, aging population, as a consequence of decreasing fertility rate and increasing life expectancy, is largely a global phenomenon. By 2040, median age of the total populations in more developed regions ${ }^{27}$ will reach 44.7 years. ${ }^{28}$

27 Europe, Northern America, Australia/New Zealand and Japan.

28 United Nations, Department of Economic and Social Affairs, Population Division (2017). World Population Prospects: The 2017 Revision, DVD Edition. 


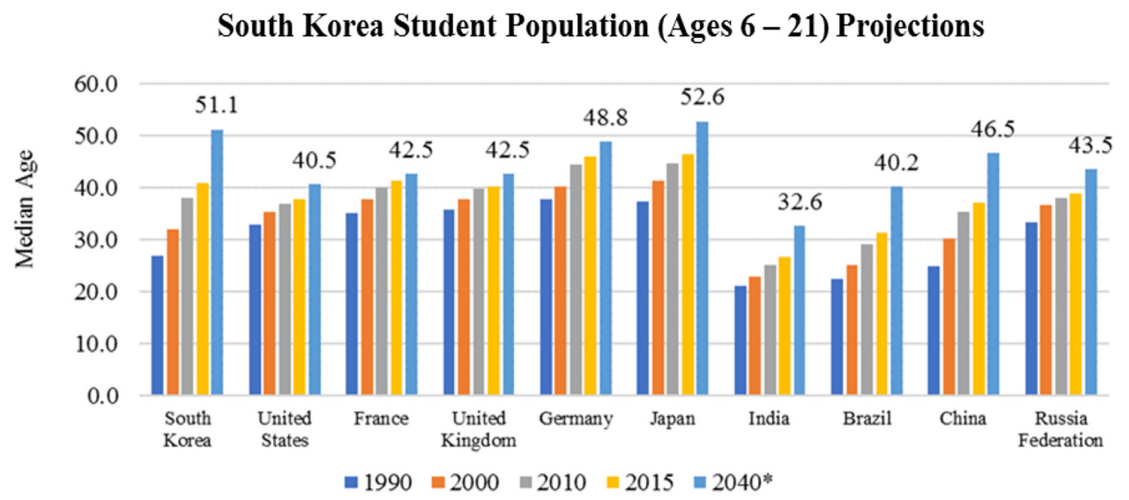

United Nations, Department of Economic and Social Affairs, Population Division (2017). World Population Prospects: The 2017 Revision, DVD Edition

*2040 estimate assumes constant-fertility and constant mortality

Decision-making under risk or uncertainty has increasingly important implications for the global aging population. Two of the most obvious areas of impact are healthcare and wealth management. Health care spending for each member of the 65 and older population was $\$ 18,988$ in 2012 , over 5 times higher than that of a child $(\$ 3,552)$ and approximately three times that of a working-age person $(\$ 6,632)(C M S, 2017)$. 


\section{Appendix B: World Values Survey}

\section{Survey Questions}

1. Please indicate your date of birth (Month/Day/Year):

2. What is your gender?
1. Female
2. Male
3. Prefer to self-describe
4. Prefer not to say

\section{Please specify your ethnicity}

1. White

2. Hispanic or Latino

3. Black or African American

4. Native American or American Indian

5. Asian / Pacific Islander

6. Other

4. What is the highest educational level that you have attained?

1. No formal education

2. Less than high school degree

3. High school degree or equivalent (e.g. GED)

4. Some college but no degree

5. Associate degree

6. Bachelor's degree 
5. For each of the following, indicate how important it is in your life. Circle your answer below.

\begin{tabular}{|l|c|c|c|c|}
\hline Categories & $\begin{array}{c}\text { Very } \\
\text { Important }\end{array}$ & $\begin{array}{c}\text { Rather } \\
\text { Important }\end{array}$ & $\begin{array}{c}\text { Not Very } \\
\text { Important }\end{array}$ & $\begin{array}{c}\text { Not at all } \\
\text { Important }\end{array}$ \\
\hline Family & 1 & 2 & 3 & 4 \\
\hline Friends & 1 & 2 & 3 & 4 \\
\hline Leisure Time & 1 & 2 & 3 & 4 \\
\hline Politics & 1 & 2 & 3 & 4 \\
\hline Work & 1 & 2 & 3 & 4 \\
\hline Religion & 1 & 2 & 3 & 4 \\
\hline
\end{tabular}

6. Generally speaking, do you usually consider yourself a Republican, a Democrat, an Independent, or what?
1. Republican
2. Democrat
3. Independent
4. Other party
5. No party
6. Not sure

Record your answer here

7. How would you describe your views on most political matters? Generally, do you think of yourself as liberal, moderate, or conservative?

1. Liberal

2. Moderate

3. Conservative

4. Not sure

Record your answer here 
8. Have you had any children?

$\begin{array}{ll}\text { No children } & 0 \\ \text { One child } & 1 \\ \text { Two children } & 2 \\ \text { Three children } & 3 \\ \text { Four children } & 4 \\ \text { Five children } & 5 \\ \text { Six children } & 6 \\ \text { Seven children } & 7 \\ \text { Eight or more children } & 8+\end{array}$

Record your answer here

9. How satisfied are you with the financial situation of your household? Completely dissatisfied Completely satisfied $\begin{array}{llllllllll}1 & 2 & 3 & 4 & 5 & 6 & 7 & 8 & 9 & 10\end{array}$ Record your answer here

10. People sometimes describe themselves as belonging to the working class, the middle class, or the upper or lower class. Which group would you describe yourself as belonging to?

1. Upper class

2. Upper middle class

3. Lower middle class

4. Working class

5. Lower class

Record your answer here 
11. Do you belong to a religion or religious denomination? If yes, which one?

No: do not belong to a denomination 0

Roman Catholic 1

Protestant 2

Orthodox (Russian/Greek/etc.) 3

Jew 4

Muslim 5

Hindu 6

Buddhist 7

Other 8

Record your answer here

12. Independently of whether you attend religious services or not, would you say you are

1. A religious person

2. Not a religious person

3. An atheist

Record your answer here 


\section{Appendix C: Lottery Questions}

Choice and Behavior Study Informed Consent Statement

Study Title: Decision Making Under Risk: Application of Prospect Theory to Eldercare

Researcher(s): Samuel Joo and Suyoung Baek

Description of Study: Participants of the study will play a game, in which are 20 different pairs of lotteries. Each participant is instructed to evaluate the outcomes of each pair of lotteries and their corresponding probabilities and then choose one of the two lottery choices.

To participate in this research study, it is necessary that you give your informed consent. By signing this informed consent statement, you are indicating that you understand the nature of the research study and your role in that research and that you agree to participate in the research. Please consider the following points before signing:

I understand that I am participating in psychological research;

I understand that my identity will not be linked with my data, and that all information I provide will remain confidential;

I understand that I will be provided with an explanation of the research in which I participated and be given the name and telephone number of an individual to contact if I have questions about the research. In addition, I understand that I may contact the Research Fellow, Samuel Joo, at xxx$\mathrm{xxx}-\mathrm{xxxx}$, if I have questions concerning my rights as a participant in psychological research;

I understand that participation in research is not required, is voluntary, and that, after any individual research project has begun, I may refuse to participate further without penalty.

By signing this form, I am stating that I am over 18 years of age, and that I understand the above information and consent to participate in this study.

Signature:

Today's Date: 


\section{The Lottery Game: Instructions}

You are provided with 20 pairs of lotteries (Lottery 1 and Lottery 2)

For each pair, choose which lottery you prefer by entering 1 or 2 in the green column

(1 if you prefer Lottery 1 and 2 if you prefer Lottery 2 )

For example, the following pair presents a lottery that offers a $30 \%$ chance of winning $\$ 200$ or a lottery that offers $90 \%$ chance of winning $\$ 40$. If you prefer the first lottery, you would write " 1 " in the green box. If you prefer the second lottery, you would write " 2 " in the green box.

\begin{tabular}{|c|c|c|c|c|c|c|c|}
\hline & \multicolumn{3}{|c|}{ Lottery 1} & \multirow[t]{2}{*}{ OR } & \multicolumn{3}{|c|}{ Lottery 2} \\
\hline 1. & $40 \%$ & $\begin{array}{l}\text { chance of } \\
\text { winning }\end{array}$ & $\$ 120$ & & $100 \%$ & $\begin{array}{l}\text { chance of } \\
\text { winning }\end{array}$ & $\$ 50$ \\
\hline 2. & $44 \%$ & $\begin{array}{c}\text { chance of } \\
\text { winning }\end{array}$ & $\$ 60$ & & $17 \%$ & $\begin{array}{l}\text { chance of } \\
\text { winning }\end{array}$ & $\$ 90$ \\
\hline 3. & $100 \%$ & $\begin{array}{l}\text { chance of } \\
\text { winning }\end{array}$ & $\$ 10$ & & $2 \%$ & $\begin{array}{l}\text { chance of } \\
\text { winning }\end{array}$ & $\$ 200$ \\
\hline 4. & $100 \%$ & $\begin{array}{l}\text { chance of } \\
\text { winning }\end{array}$ & $\$ 30$ & & $30 \%$ & $\begin{array}{l}\text { chance of } \\
\text { winning }\end{array}$ & $\$ 100$ \\
\hline 5. & $100 \%$ & $\begin{array}{l}\text { chance of } \\
\text { winning }\end{array}$ & $\$ 150$ & & $98 \%$ & $\begin{array}{l}\text { chance of } \\
\text { winning }\end{array}$ & $\$ 160$ \\
\hline 6. & $100 \%$ & $\begin{array}{l}\text { chance of } \\
\text { winning }\end{array}$ & $\$ 10$ & & $4 \%$ & $\begin{array}{l}\text { chance of } \\
\text { winning }\end{array}$ & $\$ 170$ \\
\hline 7. & $90 \%$ & $\begin{array}{l}\text { chance of } \\
\text { winning }\end{array}$ & $\$ 50$ & & $100 \%$ & $\begin{array}{l}\text { chance of } \\
\text { winning }\end{array}$ & $\$ 40$ \\
\hline 8. & $100 \%$ & $\begin{array}{l}\text { chance of } \\
\text { winning }\end{array}$ & $\$ 110$ & & $70 \%$ & $\begin{array}{l}\text { chance of } \\
\text { winning }\end{array}$ & $\$ 150$ \\
\hline 9. & $9 \%$ & $\begin{array}{l}\text { chance of } \\
\text { winning }\end{array}$ & $\$ 180$ & & $64 \%$ & $\begin{array}{l}\text { chance of } \\
\text { winning }\end{array}$ & $\$ 120$ \\
\hline 10. & $100 \%$ & $\begin{array}{l}\text { chance of } \\
\text { winning }\end{array}$ & $\$ 200$ & & $60 \%$ & $\begin{array}{l}\text { chance of } \\
\text { winning }\end{array}$ & $\$ 30$ \\
\hline 11. & $87 \%$ & $\begin{array}{l}\text { chance of } \\
\text { winning }\end{array}$ & $\$ 120$ & & $86 \%$ & $\begin{array}{l}\text { chance of } \\
\text { winning }\end{array}$ & $\$ 190$ \\
\hline
\end{tabular}


Samuel Joo \& Suyoung Baek

\begin{tabular}{|l|c|c|c|c|c|c|c|}
\hline & \multicolumn{3}{|c|}{ Lottery 1 } & OR & \multicolumn{3}{c|}{ Lottery 2 } \\
\hline 12. & $2 \%$ & $\begin{array}{c}\text { chance of } \\
\text { winning }\end{array}$ & $\$ 80$ & & $29 \%$ & $\begin{array}{c}\text { chance of } \\
\text { winning }\end{array}$ & $\$ 40$ \\
\hline 13. & $100 \%$ & $\begin{array}{c}\text { chance of } \\
\text { winning }\end{array}$ & $\$ 20$ & & $10 \%$ & $\begin{array}{c}\text { chance of } \\
\text { winning }\end{array}$ & $\$ 150$ \\
\hline 14. & $100 \%$ & $\begin{array}{c}\text { chance of } \\
\text { winning }\end{array}$ & $\$ 10$ & & $97 \%$ & $\begin{array}{c}\text { chance of } \\
\text { winning }\end{array}$ & $\$ 20$ \\
\hline 15. & $31 \%$ & $\begin{array}{c}\text { chance of } \\
\text { winning }\end{array}$ & $\$ 100$ & & $74 \%$ & $\begin{array}{c}\text { chance of } \\
\text { winning }\end{array}$ & $\$ 60$ \\
\hline 16. & $100 \%$ & $\begin{array}{c}\text { chance of } \\
\text { winning }\end{array}$ & $\$ 10$ & & $5 \%$ & $\begin{array}{c}\text { chance of } \\
\text { winning }\end{array}$ & $\$ 120$ \\
\hline 17. & $7 \%$ & $\begin{array}{c}\text { chance of } \\
\text { winning }\end{array}$ & $\$ 150$ & & $100 \%$ & $\begin{array}{c}\text { chance of } \\
\text { winning }\end{array}$ & $\$ 90$ \\
\hline 18. & $50 \%$ & $\begin{array}{c}\text { chance of } \\
\text { winning }\end{array}$ & $\$ 180$ & & $100 \%$ & $\begin{array}{l}\text { chance of } \\
\text { winning }\end{array}$ & $\$ 90$ \\
\hline 19. & $79 \%$ & $\begin{array}{c}\text { chance of } \\
\text { winning }\end{array}$ & $\$ 20$ & & $44 \%$ & $\begin{array}{l}\text { chance of } \\
\text { winning }\end{array}$ & $\$ 150$ \\
\hline 20. & $100 \%$ & $\begin{array}{c}\text { chance of } \\
\text { winning }\end{array}$ & $\$ 140$ & & $65 \%$ & $\begin{array}{c}\text { chance of } \\
\text { winning }\end{array}$ & $\$ 90$ \\
\hline
\end{tabular}

